Article

\title{
Selection of Dedicated As-Cast Microstructures in Zn-Al-Cu Alloys for Bearing Applications Supported by Phase-Field Simulations
}

\author{
Steffen Gimmler ${ }^{1, *}$, Markus Apel ${ }^{2}$ (D) and Andreas Bührig-Polaczek ${ }^{1}$ \\ 1 Foundry Institute, RWTH Aachen University, 52072 Aachen, Germany; sekretariat@gi.rwth-aachen.de \\ 2 ACCESS e.V., 52072 Aachen, Germany; m.apel@access-technology.de \\ * Correspondence: s.gimmler@gi.rwth-aachen.de; Tel.: +49-241-80-98910
}

Received: 11 November 2020; Accepted: 7 December 2020; Published: 10 December 2020

\begin{abstract}
Solidification and phase formation of $\mathrm{Zn}$-rich $\mathrm{Zn}-\mathrm{Al}-\mathrm{Cu}$ alloys with different $\mathrm{Al}$ and $\mathrm{Cu}$ contents were investigated. The investigations comprise alloy compositions with either hcp $\eta$, fcc $\alpha$ or hcp $\varepsilon$ as the primary phase, as well as a composition close to the ternary eutectic point. Test samples were produced in a mold casting process and their microstructures were investigated by scanning electron microscopy. Experimental microstructures are compared with the results from spatially resolved microstructure simulations using a phase-field model. In particular, the dependency between the aluminum and copper contents and the phase fractions of the $\eta, \alpha$ and $\varepsilon$ phases were analyzed. In addition, hardness tests for the samples prove a direct correlation between the $\alpha$ - and $\varepsilon$-phase fractions with the macroscopic hardness of the alloys. A simple model, based on the phase fractions and the properties of the single phases, is suggested for the computation of hardness from the simulation results in order to select appropriate alloy compositions for bearing applications.
\end{abstract}

Keywords: bearing alloys; as-cast microstructure; phase-field simulations

\section{Introduction}

Due to the steady increasing demands for efficiency and economy, the currently used plain bearing materials are increasingly reaching their limits in terms of mechanical and thermal load capacity [1]. In this context, $\mathrm{Zn}$-Al-Cu alloys represent a very promising basis for significantly out-performing conventional white metal alloys in terms of both thermal and mechanical stability, without neglecting the core properties of plain bearings, such as dry sliding properties and adaptability [2]. In general, Zn-Al-alloys show a high compressive strength combined with good tribological properties, such as low friction coefficients and high wear resistance [3-6]. In order to control the mechanical and tribological properties of these alloys in cast bearing components, knowledge of the microstructure formation along the solidification is essential.

$\mathrm{Zn}$-rich binary $\mathrm{Zn}-\mathrm{Al}$ alloys are eutectic alloys. In the hypoeutectic range with aluminum contents below $5 \mathrm{wt} . \%$, they solidify primarily in the hexagonal zinc phase $\eta$, while in the hypereutectic range, they solidify primarily in the zinc-rich face-centered cubic $\beta$ phase. Below the eutectic temperature of $382{ }^{\circ} \mathrm{C}$, solidification terminates with a eutectic microstructure composed of $\eta$ and $\beta$ phases. When the temperature falls below $275^{\circ} \mathrm{C}$, the $\beta$ phase becomes unstable and de-composes via a eutectoid reaction into a fine lamellar microstructure of the $\eta$ phase and the aluminum-rich fcc- $\alpha$ phase $[7,8]$.

Stepping towards a ternary system by the addition of copper yields a ternary eutectic in the $\mathrm{Zn}$-rich corner. Figure 1 depicts an isothermal section and the liquidus projection of the $\mathrm{Zn}$-rich corner, calculated from the CALPHAD data derived from [9]. The isothermal section at $375{ }^{\circ} \mathrm{C}$ is slightly below

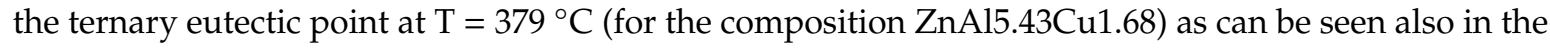


liquidus projection. The four different alloys which have been investigated by phase-field simulations in this paper are marked by filled circles. According to the equilibrium phase diagram, two of these alloys are binary eutectics, and one is located in the single $\beta$-phase region. The alloy ZnAl5.5Cu4 (blue dot) is close to the ternary eutectic composition. The addition of a few wt.\% copper results not only in a significant increase in strength, presumably due to solid solution hardening, but also in the formation of the intermetallic $\varepsilon$ phase when the copper concentration exceeds $2 \mathrm{wt}$.\%. The $\varepsilon$ phase of the composition $\mathrm{Zn} 4 \mathrm{Cu}$ additionally leads to an increasing strength and hardness as well $[5,10,11]$.

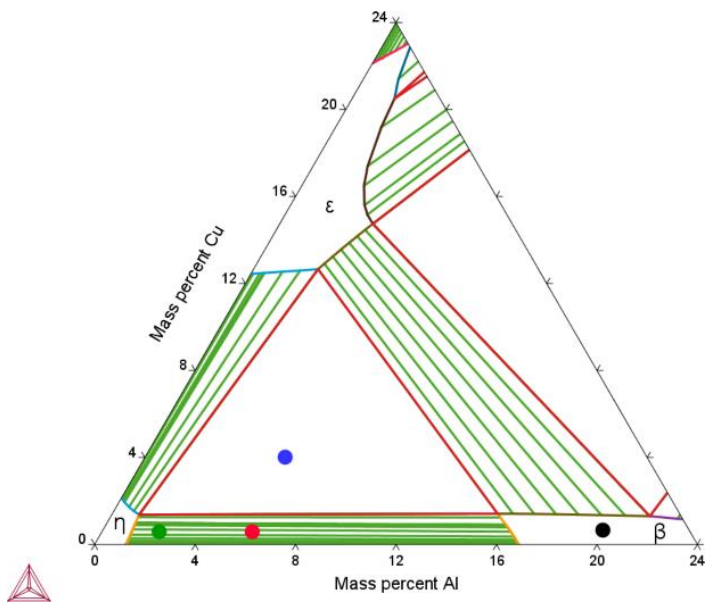

(a)

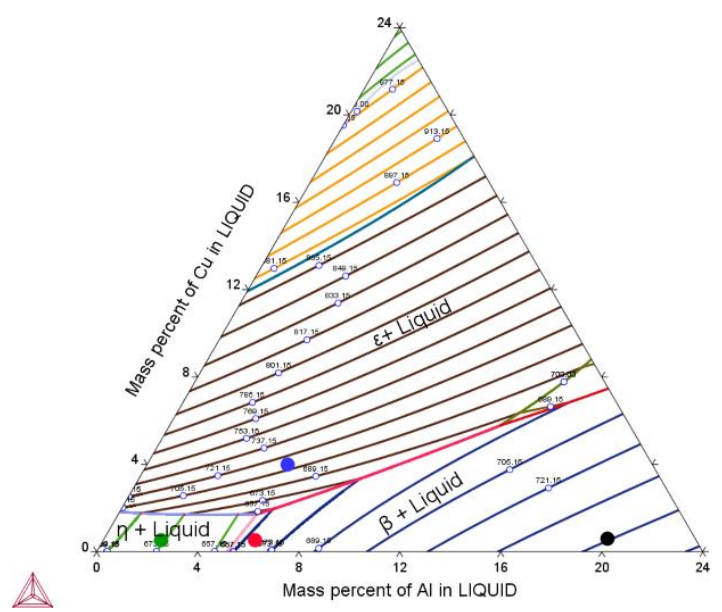

(b)

Figure 1. Computed isothermal section at $\mathrm{T}=375^{\circ} \mathrm{C}$ of the $\mathrm{Zn}$-rich $\mathrm{Zn}$-Al-Cu phase diagram based on the CALPHAD data from [9] (a). The four different alloy compositions investigated in this paper are marked by the filled circles. Computed liquidus projection $(\mathbf{b})$.

The $\varepsilon$ phase is only stable at elevated temperatures, i.e., during and after solidification. Upon further cooling, it tends to react with the surrounding phases through thermally activated de-composition processes via

$$
\varepsilon+\alpha \rightarrow \eta+\mathrm{T}^{\prime}
$$

where $\mathrm{T}^{\prime}$ is a stable rhombohedral phase of the composition $\mathrm{Al} \mathrm{Zn} 4 \mathrm{Cu}[12,13]$.

However, the transformation of the $\varepsilon$ phase can almost be completely bypassed by high cooling rates, so that, depending on the cooling conditions at room temperature, both $\varepsilon$ and $\mathrm{T}^{\prime}$ phases can be present $[8,14]$.

In this paper, the microstructure evolution will be elucidated by a combined approach of casting experiments, thermodynamic equilibrium calculations and thermodynamic coupled phase-field simulations. The major aim is a quantitative correlation between alloy composition and microstructure. Compared to thermodynamic equilibrium calculations, the phase-field method does not only take into account the effect of different cooling rates on phase fractions, but also provides spatially resolved predictions of the microstructure, in particular also for the alloying element distribution, i.e., microsegregation. Thus, phase-field results set the basis for more sophisticated material property models beyond simplified mixture rules. The correlation between "local" hardness and the local $\mathrm{Cu}$ concentration suggests that the $\mathrm{Cu}$ concentration is the major factor determining the hardness of the alloy.

The combined experimental and computational approach enables tailoring complex three-phase microstructures with a rich variety of even qualitatively different morphologies and therefore a broad spectrum of material properties. The consideration of the solidification kinetic by phase-field simulations is especially important for manufacturing processes showing fast cooling rates, e.g., build-up welding. This will become important when transferring the results from alloy development to production processes for different bearing components. 


\section{Materials and Methods}

\subsection{Sample Preparation and Testing Methods}

Samples of different compositions were produced by melting pure zinc ( $\mathrm{Zn} \mathrm{99.995 \% ),}$ pure aluminum (99.8\%) and pure copper (99.99\%) in an induction furnace and casting the homogenized melt in a cold steel die to reach high cooling rates of about $0.8^{\circ} \mathrm{C} / \mathrm{s}$. The overheating was kept constant for all compositions, obtaining comparable casting conditions. Samples were prepared by means of selected grinding and polishing steps with intermediate etching before final polishing to minimize the formation of deformation layers [15].

The microstructures of these samples were examined by scanning electron microscopy (SEM) (Zeiss, Oberkochen, Germany) and energy dispersive X-ray spectroscopy (EDS) (Oxford Instruments, Wiesbaden, Germany) analysis for the morphology and composition of the resulting phases. The Vickers hardness of the individual phases was determined by microhardness measurements (Anton Paar $\mathrm{MHT}^{3}$ ), whereas Brinell hardness measurements (Karl Frank GmbH, Weinheim, Germany) were carried out to determine the macroscopic hardness of the samples.

\subsection{Phase-Field Model}

A multiphase-field model was used for spatially and temporally resolved simulations of the microstructure evolution during solidification. In addition to the microstructure, phase-field simulations provide the local element concentration and a quantitative prediction of phase fractions, not only in a 2D slice as in standard metallography, but integrated over a small representative volume of the microstructure. Simulations were performed with the software MICRESS (Version 7.0, ACCESS e.V., Aachen, Germany) [16]. The phase-field model in MICRESS is linked to a thermodynamic CALPHAD database for Al-Cu-Zn [9] and enables quantitative calculations of thermodynamic driving forces and element partitioning between the different phases. The phase-field model and the corresponding evolution equations are described in more detail in a series of papers [17-21]. Further information about the equations is also available in the MICRESS documentation which is freely accessible on the website [16].

Beside the thermodynamic data, further material-related properties as listed in Table 1 were the input data for the simulations. For the diffusion coefficients of $\mathrm{Al}$ and $\mathrm{Cu}$ in the ternary system $\mathrm{Zn}-\mathrm{Al}-\mathrm{Cu}$ and the interfacial energies, no precise data could be found in the literature; hence, the values applied in the simulations are "educated guesses" with an estimated error of about a factor of 2 for the interfacial energies and a factor of 5 for the diffusion coefficients. The interface mobility was automatically derived from the thin interface limit during the computation to assure diffusion-controlled growth with vanishing kinetic undercooling [21]. Further, an anti-trapping current was added to the diffusion equation to reduce diffuse interface artifacts [21].

Table 1. Material parameters used for the phase-field simulations.

\begin{tabular}{|c|c|c|c|}
\hline \multicolumn{2}{|c|}{ Diffusion Coefficients } & \multicolumn{2}{|c|}{ Interfacial Energy } \\
\hline $\mathrm{Al}$ in melt & $2 \times 10^{-6} \mathrm{~cm}^{2} / \mathrm{s}$ & solid phases/melt & $2.5 \times 10^{-5} \mathrm{~J} / \mathrm{cm}^{2}$ \\
\hline $\mathrm{Cu}$ in melt & $2 \times 10^{-6} \mathrm{~cm}^{2} / \mathrm{s}$ & solid/solid interfaces & $2.5 \times 10^{-5} \mathrm{~J} / \mathrm{cm}^{2}$ \\
\hline $\mathrm{Al}$ in all solid phases & $3.1 \times 10^{-9} \mathrm{~cm}^{2} / \mathrm{s}$ & \multicolumn{2}{|c|}{ interfacial anisotropies } \\
\hline $\mathrm{Cu}$ in all solid phases & $3.1 \times 10^{-9} \mathrm{~cm}^{2} / \mathrm{s}$ & $\beta-\mathrm{Al}$ (Zn-rich) & cubic \\
\hline \multirow{2}{*}{\multicolumn{2}{|c|}{$\begin{array}{c}- \\
\text { Interface mobility for solid/melt interfaces }\end{array}$}} & $\eta-\mathrm{Zn}$ and $\varepsilon-\mathrm{Zn} 4 \mathrm{Cu}$ & hexagonal \\
\hline & & \multicolumn{2}{|c|}{$\infty$ according to the thin interface limit [21] } \\
\hline
\end{tabular}

The comparison of the simulation results with the experimental micrographs presented in Section 3 shows that the single dataset from Table 1 leads to a reasonable match for all different alloy compositions. However, at this stage, the simulations should be considered as semi-quantitative. A systematic and 
quantitative comparison between experimental and simulated microstructures offers the opportunity to derive the unknown values with a higher accuracy, which is beyond the scope of this work.

The size of the 3D simulation domain is $100 \mu \mathrm{m} \times 50 \mu \mathrm{m} \times 100 \mu \mathrm{m}$ with a uniform grid spacing $\Delta \mathrm{x}=0.25 \mu \mathrm{m}$ for all simulations. The phase-field interface thickness is 3 grid cells which is possible by a special finite difference discretization schema [22].

The temperature profiles were calculated via an energy balance equation, balancing an external heat flux given as an input parameter, the release of latent heat and the heat capacity under the assumption of negligible thermal gradients, i.e., the heat conduction is fast enough to maintain a uniform temperature in the simulation domain. By this approach, the cooling curve is a result of the simulation and allows a quantitative comparison with experimental data. A constant heat extraction rate of $65 \mathrm{~W} / \mathrm{cm}^{3}$ holds for all simulations shown in this paper. The corresponding solidification time, i.e., the time between $\mathrm{T}_{\text {liquidus }}$ and $\mathrm{T}_{\text {solidius, }}$ is around $15 \mathrm{~s}$ and close to the experimental values measured for permanent mold castings. The exact value for the solidification time depends on the alloy composition (see, e.g., Figure 2).

The simulations comprise the formation of the three solid phases $\beta-\mathrm{fcc}, \eta-\mathrm{Zn}$ (hcp) and $\varepsilon-\mathrm{Zn} 4 \mathrm{Cu}$ (hcp) and show the microstructure evolution along the solidification path until the end of solidification. Solid-state transformations at lower temperatures are not considered yet. Nucleation is described by a phenomenological nucleation model [19], which is based on a predefined critical nucleation undercooling $\Delta \mathrm{T}_{\text {nuc }}$ and a minimal closest distance $\mathrm{d}_{\text {min }}$ between neighboring nuclei with $\Delta \mathrm{T}_{\text {nuc }}=3 \mathrm{~K}$ and $\mathrm{d}_{\min }=40 \mu \mathrm{m}$ for all simulations.

An example for the temporal evolution of a solidification microstructure is shown in Figure 2 for the alloy composition $\mathrm{Zn} 20 \mathrm{Al} 10.7 \mathrm{Cu}$. For this alloy, $\beta$ is the first phase to nucleate. The $\mathrm{Al}$ concentration is higher in the solid $\beta$ phase compared to the melt, thus the Al concentration in the melt decreases during the course of solidification. Eventually, the $\eta$-Zn phase nucleates between the $\beta$-dendrites. This phase dissolves only a minor amount of $\mathrm{Al}$ and appears dark blue in the 3D representation in Figure 2. Depending on the overall eutectic fraction and thus on the alloy composition, $\eta-\mathrm{Zn}$ and $\beta$ phases partly form a "divorced eutectic" microstructure instead of a lamellar growth structure. Upon further cooling, the primary Zn-rich $\beta$ phase decomposes into $\eta$-Zn and Al-rich $\alpha^{\prime}$-fcc Al by a eutectoid reaction which is not part of the current simulation scenario.

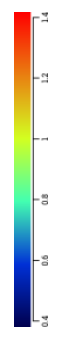

[Al]

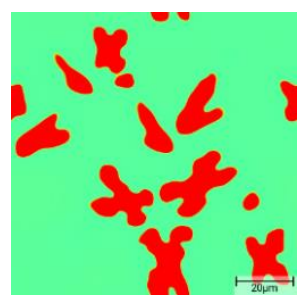

$\mathrm{t}=5 \mathrm{~s}$

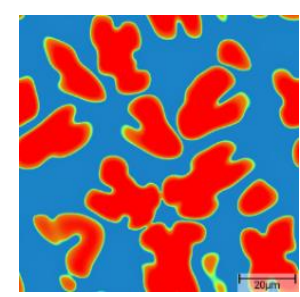

$\mathrm{t}=10 \mathrm{~s}$

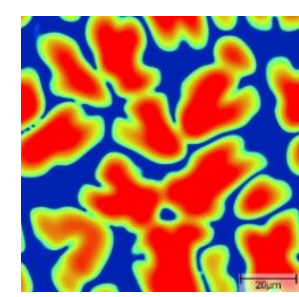

$t=15 s$

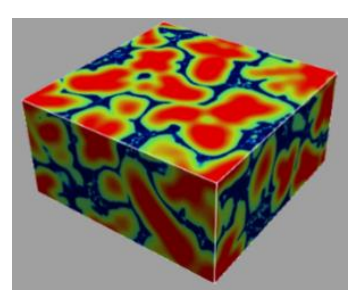

$\mathrm{t}=18 \mathrm{~s}, 3 \mathrm{D}$ representation

Figure 2. Microstructure evolution in $\mathrm{Zn} 20 \mathrm{Al} 10.7 \mathrm{Cu}$ during solidification represented by the $\mathrm{Al}$ concentration. Size of the 2D cutting plane in the middle of the 3D box: $100 \mu \mathrm{m} \times 100 \mu \mathrm{m}$.

\subsection{Hardness Computation Model}

In order to derive the macroscopic hardness from the simulated microstructures, we propose a correlation between the phase fractions and hardness based on a mixture rule:

$$
\mathrm{HB}^{\mathrm{i}}=\sum_{\mathrm{i}} \mathrm{f}_{\mathrm{i}} \cdot\left(\mathrm{HB}_{0}^{\mathrm{i}}+\mathrm{a}^{\mathrm{i}} \cdot[\mathrm{Cu}]^{\mathrm{i}}\right)
$$


where $i=\beta, \eta$ or $\varepsilon, \mathrm{HB}_{0}^{i}$ is the hardness of the pure binary phase $i$ without $\mathrm{Cu}$ and $[\mathrm{Cu}]^{\mathrm{i}}$ is the average $\mathrm{Cu}$ composition of phase $\mathrm{i}$ as derived from the phase-field simulations. The constants $\mathrm{a}^{\mathrm{i}}$ are $\mathrm{a}$ model parameter.

\section{Results and Discussions}

\subsection{Simulated Solidification Path}

The graph in Figure 3a shows the simulated evolution of the phase fractions as a function of temperature, and the corresponding cooling curves are shown in Figure $3 \mathrm{~b}$. The left graph shows

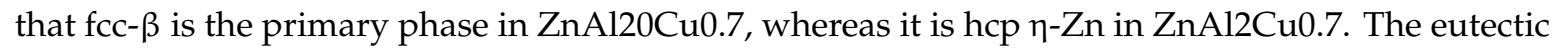
temperature is $379^{\circ} \mathrm{C}$ and clearly marked as a steep increase in the phase fractions and a temperature plateau in the cooling curves. Recalescence is visible at the beginning of the primary solidification,

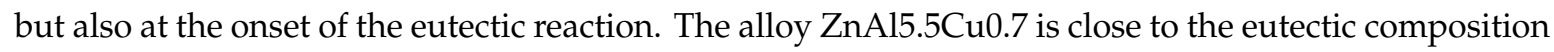
and thus characterized by a vanishing solidification interval.

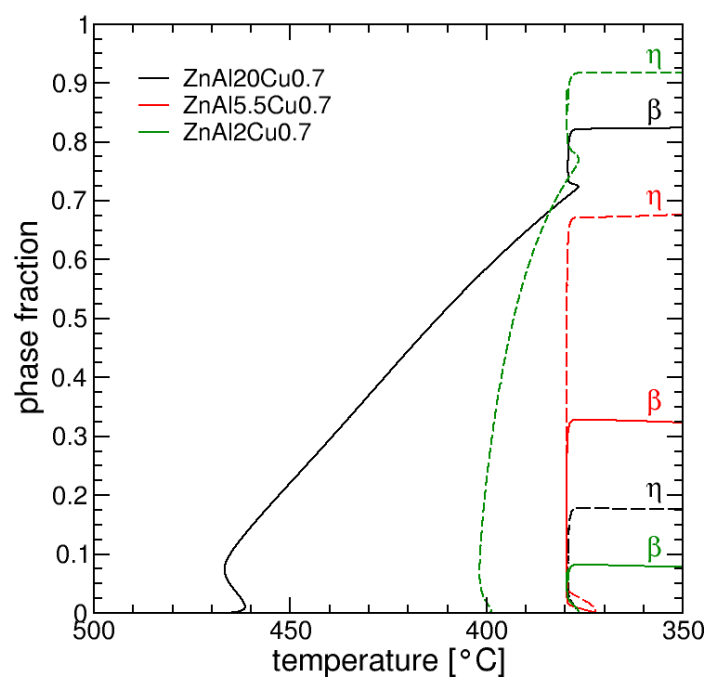

(a)

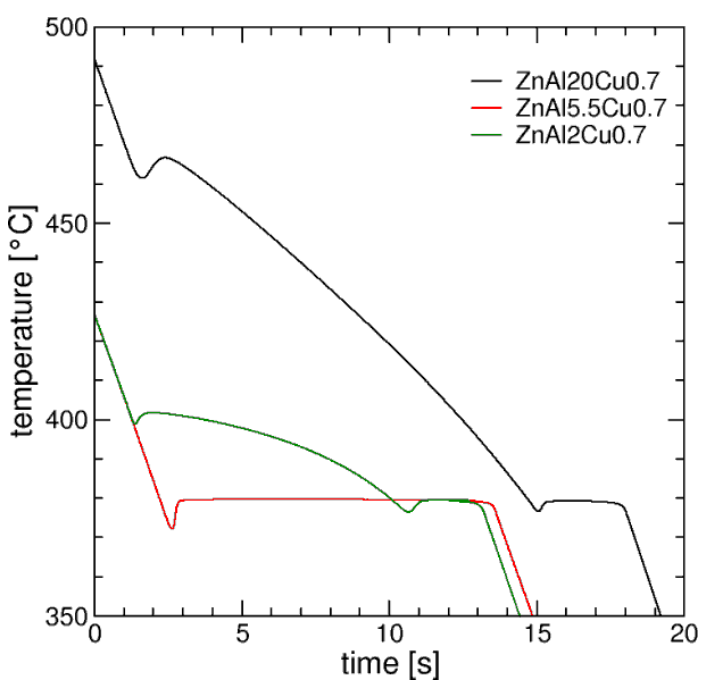

(b)

Figure 3. (a) Phase fractions versus temperature for three alloys with different $\mathrm{Al}$ compositions ( $\beta$ denotes the fcc-phase, $\eta$ the hcp-Zn phase). (b) Temperature versus time for the three alloys as derived from the simulations.

The three alloys demonstrate the rich variety of possible microstructures in this alloy system, as can be seen in the next section.

\subsection{Correlation between Alloy Composition and Microstructure}

Alloys with different aluminum and constant copper contents were cast in a first step. Like in the

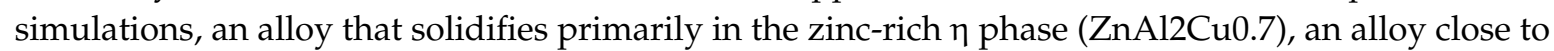
the ternary eutectic $(\mathrm{ZnAl5} .5 \mathrm{Cu} 0.7)$ and an alloy with primary $\beta$-phase solidification $(\mathrm{ZnAl20Cu0.7)}$ were examined.

Cooling curves recorded during the casting process give information about the heat extraction rate, which can be used as a process condition for the phase-field simulations. In Figure 4, an SEM image of the microstructure of the alloy $\mathrm{ZnAl} 2 \mathrm{Cu} 0.7$, which primarily solidifies in the $\eta$ phase, is compared with the simulation results.

The comparison shows a good agreement regarding major microstructural features. Primary $\eta$-dendrites surrounded by the eutectic are visible with comparable phase fractions and dendrite arm spacings of about $25 \mu \mathrm{m}$. The dendritic grain structure is close to globular, i.e., primary trunk and 
side arms are difficult to distinguish in the $2 \mathrm{D}$ section. The phase-field simulation calculates phase fractions of $92 \% \eta$ and $8 \% \beta$ in the as-solidified microstructure. An equilibrium calculation with the same database yields $6.1 \% \beta$, suggesting that the solidification takes place rather close to equilibrium. The microsegregation pattern for $\mathrm{Cu}$ shows that $\mathrm{Cu}$ accumulates in areas of the microstructure that solidify last, in particular at the boundaries between eutectic cells. In larger interdendritic areas, the eutectic microstructure is rather lamellar, but due to the geometrical constraint by the primary dendritic network, fibrous or irregular eutectic patterns are present as well.

(a)

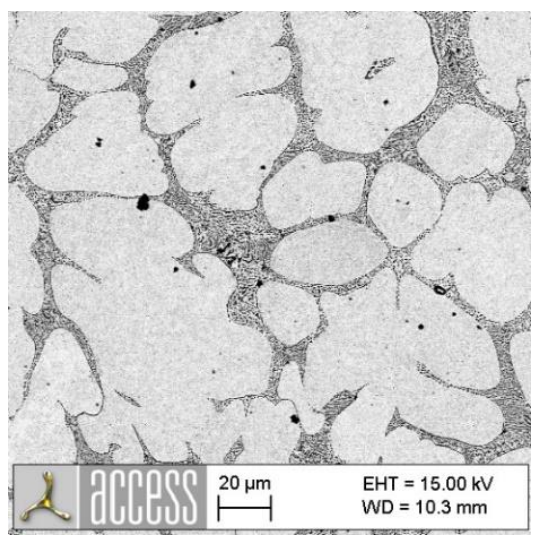

(b)

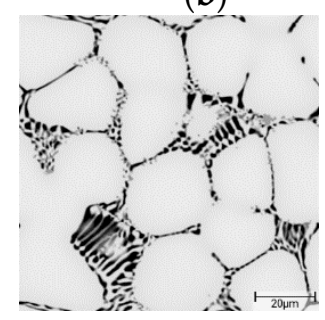

(d)

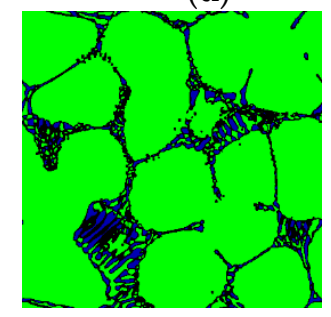

(c)

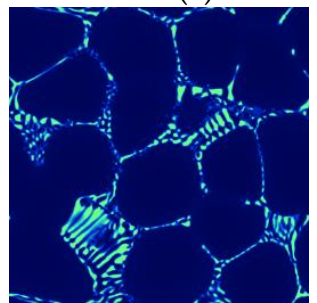

(e)

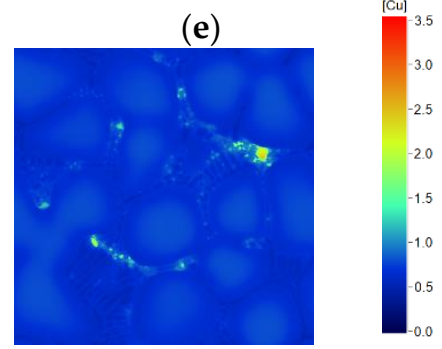

Figure 4. (a) Microstructure of $\mathrm{ZnAl} 2 \mathrm{Cu} 0.7$ in backscattered electrons (BSE) contrast; (b-e) simulated microstructure of $\mathrm{ZnAl2Cu0.7.} \mathrm{(b)} \mathrm{Al}$ (gray scale, matched contrast), (c) $\mathrm{Al}$ concentration (wt.\%), (d) phases ( $\eta$ green, $\beta$ blue) and (e) Cu concentration (wt.\%). Size of the 2D plane from the simulation: $100 \mu \mathrm{m} \times 100 \mu \mathrm{m}$.

The eutectic spacing in the simulation is slightly coarser than that found in the experiment. This suggests that either the values of the diffusion coefficients and/or the interfacial energies are too large in the simulations or that there is a difference in the cooling rates between the real casting and simulation. Beside these uncertainties, the grid resolution is another limiting factor: the finest lamella thickness which can be represented by the numerical grid is twice the phase-field interface thickness, i.e., $6 \times \Delta \mathrm{x}=1.5 \mu \mathrm{m}$. This is larger than the experimentally observed spacing. A proper resolution of the eutectic spacing would require a higher grid resolution. Due the increasing computational effort, this would be only feasible on smaller computational domains with volumes below the average grain size. However, the primary target of the phase-field simulations presented in this paper is not to predict the eutectic spacing, but to compute the phase fractions and the $\mathrm{Cu}$ microsegregation in the primary phases as input for the hardness calculation. Thus, a more detailed analysis of the eutectic microstructure is a future task which offers the opportunity to derive quantitative values for the solid/liquid interfacial energies and the diffusion coefficients of $\mathrm{Al}$ and $\mathrm{Cu}$ in the melt.

The comparison between the cast and simulated microstructures of ZnAl20Cu0.7 is shown in Figure 5. It demonstrates also for a hypereutectic alloy a good correlation between the as-cast and simulated microstructures. Both phase fractions and the shape of the phases are well represented by the simulation. Overall, the simulation calculates $82 \% \beta$ and $18 \% \eta$. In $\mathrm{ZnAl} 20 \mathrm{Cu} 0.7$, the $\beta$ phase with local $\mathrm{Al}$ concentrations up to $45 \mathrm{wt} . \%$ in the dendrite centers is the primary phase. It decomposes into the zinc-rich $\eta$ and the aluminum-rich $\alpha$ phases. The resulting eutectoid microstructure is not resolved in the SEM image shown in Figure 5, but the variation in the Al concentration leads to the contrast within the dendrites. The local Al concentration decreases from the center areas of the dendrites towards the outer areas that solidify last. The same distribution is obtained in the simulations. The qualitative 
agreement of the concentration profiles verifies that the values for the diffusion coefficients used in the simulation are at least in the right order of magnitude.

The morphology of the interdendritic eutectic exhibits a rim of $\eta$ phase around the dendrites, whereas a lamellar structure can only be formed in larger interdendritic areas. The simulation also predicts this behavior. Furthermore, $\mathrm{Cu}$ is mainly distributed within the eutectic regions.

(a)

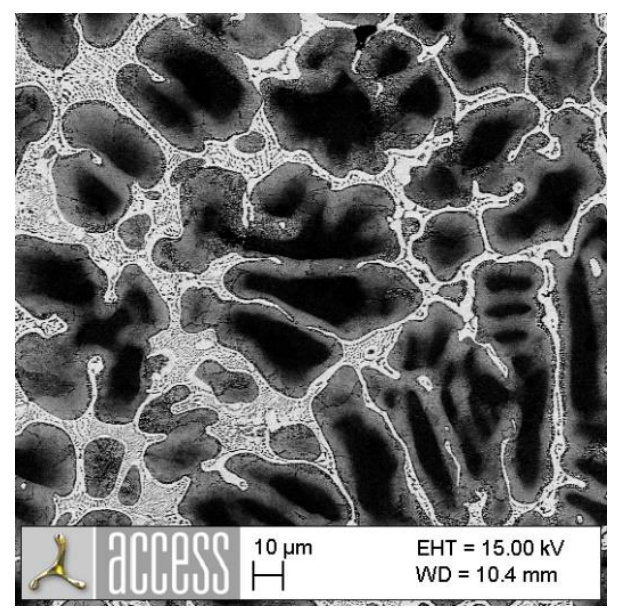

(b)

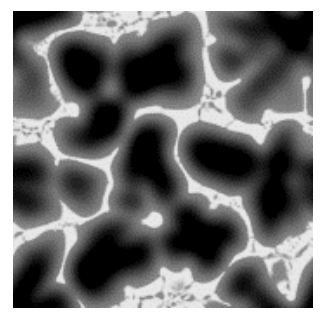

(d)

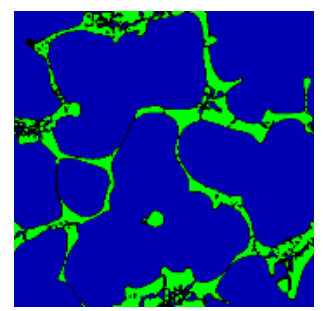

(c)

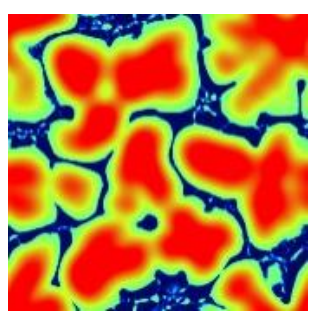

(e)

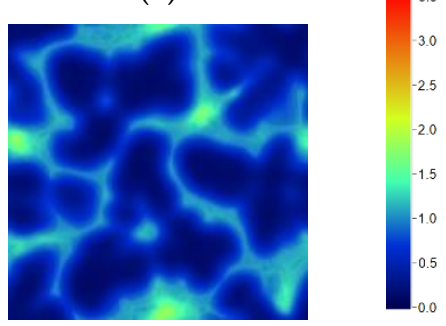

Figure 5. (a) Microstructure of $\mathrm{ZnAl} 20 \mathrm{Cu} 0.7$ in BSE contrast; (b-e) simulated microstructure of $\mathrm{ZnAl20Cu0.7.} \mathrm{(b)} \mathrm{Al} \mathrm{(gray} \mathrm{scale,} \mathrm{matched} \mathrm{contrast),} \mathrm{(c)} \mathrm{Al} \mathrm{concentration} \mathrm{(wt. \% ),} \mathrm{(d)} \mathrm{phases} \mathrm{( \eta} \mathrm{green,}$ $\beta$ blue) and (e) Cu concentration (wt.\%). Size of the 2D plane from the simulation: $100 \mu \mathrm{m} \times 100 \mu \mathrm{m}$.

The microstructure of the near-eutectic alloy $\mathrm{ZnAl} 5.5 \mathrm{cu} 0.7$ is shown in Figure 6. As already shown in Figure $3 b$, the solidification of this alloy takes place at $382{ }^{\circ} \mathrm{C}$ starting with the formation of small $\eta$ or $\beta$ nuclei which are fully surrounded by the eutectic phases. The as-cast microstructure, as well as the simulated one, again shows the same overall appearance. Both microstructures are dominated by eutectic grains. The eutectic appears lamellar or fibrous in the $2 \mathrm{D}$ cutting plane. The lamellar appearance is partly a geometrical effect due to the cutting, but also the 3D structures exhibit lamellar regions with a higher tendency in the last stages of solidification. Moreover, here, the simulated eutectic structure is coarser than the experimental ones. The local $\mathrm{Cu}$ concentration is again highest at the boundaries between eutectic grains.

For the alloys investigated in this paper, the calculated phase fractions of the $\beta$ phase are compiled in Table 2 and will later be discussed for the evaluation of the hardness computation model.

Table 2. $\beta$-phase fractions at $375{ }^{\circ} \mathrm{C}$ representing the as-cast phase fraction immediately after solidification for alloys with different aluminum concentrations.

\begin{tabular}{ccc}
\hline Alloy & $\boldsymbol{\beta}$ Phase (Simulation) [\%] & $\boldsymbol{\beta}$ Phase (Equilibrium) [\%] \\
\hline ZnAlCu0.7 & 2.0 & 0 \\
ZnAl2Cu0.7 & 8.0 & 6.6 \\
ZnAl4Cu0.7 & 21.8 & 21.8 \\
ZnAl5.5Cu0.7 & 32.9 & 32.8 \\
ZnAl11Cu0.7 & 69.7 & 69.6 \\
ZnAl20Cu0.7 & 88.7 & 100 \\
\hline
\end{tabular}


(a)

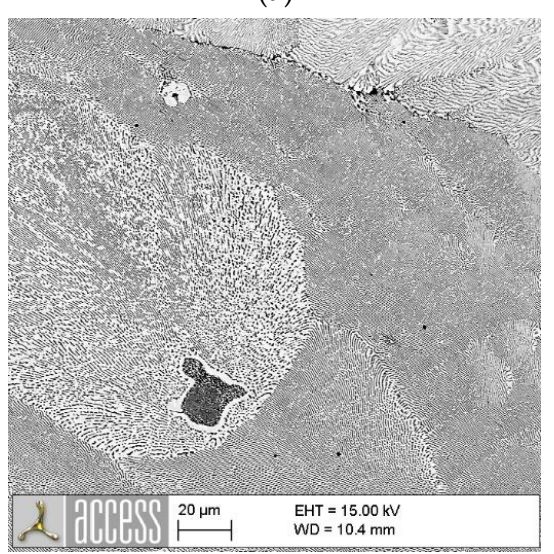

(b)

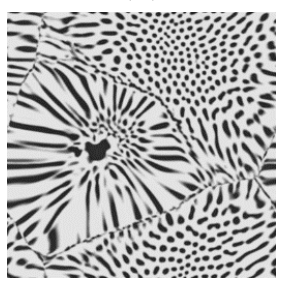

(d)

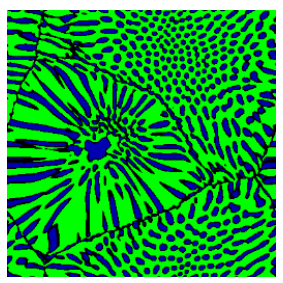

(c)

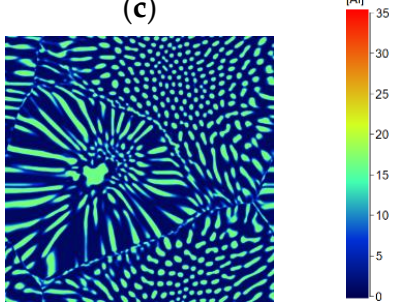

(e)

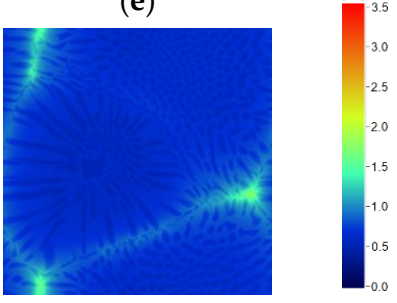

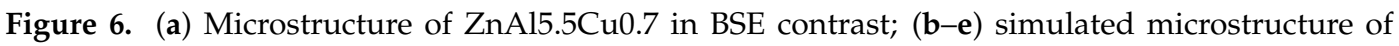
ZnAl5.5Cu0.7. (b) Al (gray scale, matched contrast), (c) Al concentration (wt.\%), (d) phases ( $\eta$ green, $\beta$ blue) and (e) $\mathrm{Cu}$ concentration (wt.\%). Size of the 2D plane from the simulation: $100 \mu \mathrm{m} \times 100 \mu \mathrm{m}$.

The comparison between phase-field results and equilibrium calculations shows a significant difference for low and high $\mathrm{Al}$ contents. The deviation is most striking for the alloy with $20 \mathrm{wt}$. $\% \mathrm{Cu}$. According to the thermodynamic equilibrium, a single $\beta$ phase is expected, however, in the experimental micrograph, a still large amount of eutectic, i.e., $\eta$ phase, is present. This is also seen in the phase-field results which show $11.3 \% \eta$. For lower Al contents, the equilibrium calculations underestimate the amount of $\beta$ phase after solidification, also in accordance with the experimental findings.

Another advantage of quantitative phase-field simulations is evident for $\mathrm{ZnAlCu}$ alloys with higher copper contents. As already mentioned, $\varepsilon-\mathrm{Zn} 4 \mathrm{Cu}$ forms at copper contents above $2 \mathrm{wt}$.\%. The $\mathrm{Zn}_{4} \mathrm{Cu}$ phase can only be identified by EDS analysis with great effort. In SE and BSE contrast, there is no visible difference between the $\eta$ phase and $\varepsilon$ phase because of the similar atomic mass of $\mathrm{Cu}$ and $\mathrm{Zn}$. Hence, the determination of the phase fractions of these two phases in an SEM analysis is accompanied by large uncertainties. With the help of phase-field simulations, phase fractions, size and distribution can be illustrated as shown in Figure 7. The figure shows a partially solidified microstructure with $62 \%$ solid fraction.

(a)

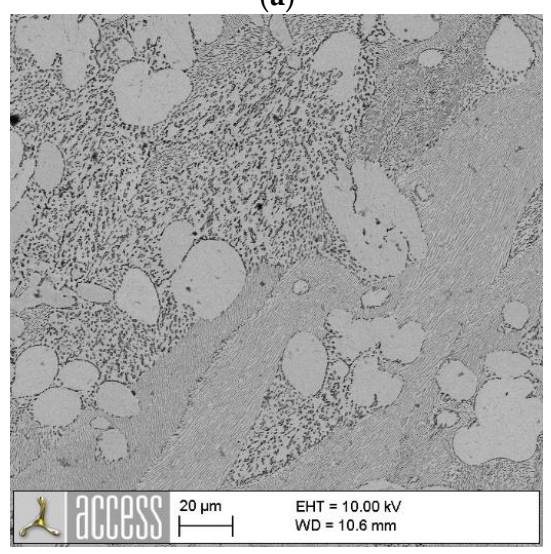

(b)

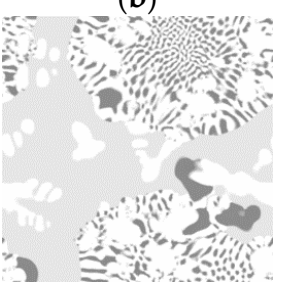

(d)

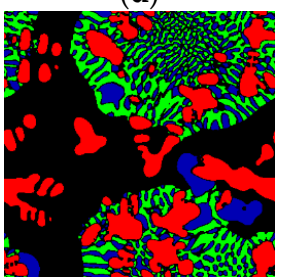

(c)

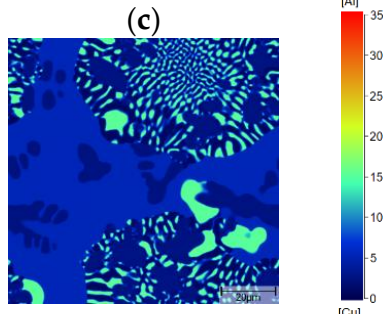

(e)

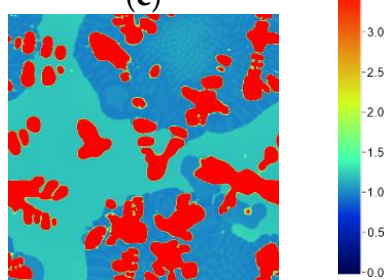

Figure 7. (a) Microstructure of ZnAl5.5Cu4 in BSE contrast. Simulated microstructure of ZnAl5.5Cu4; (b) $\mathrm{Al}$ (grey scale, matched contrast), (c) Al concentration (wt.\%), (d) phases ( $\eta$ green, $\beta$ blue, $\varepsilon$ red) and

(e) Cu concentration (wt.\%). Size of the 2D plane: $100 \mu \mathrm{m} \times 100 \mu \mathrm{m}$. 


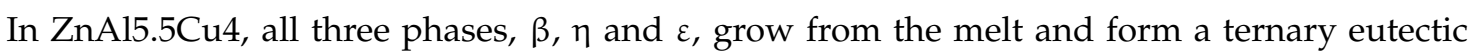
microstructure with predominantly $\varepsilon$ but also smaller fractions of $\beta$ as primary phases. In Figure 7 , the $\varepsilon$ phase appears red, $\eta$ appears green, $\beta$ appears blue and black marks the liquid. $\beta / \eta$ eutectic islands grow in between the primary $\varepsilon$ dendrites. In the BSE image, this corresponds to the coarse eutectic areas, e.g., in the upper left quadrant.

\subsection{Hardness Measurement Results}

The hardness of a material is a decisive parameter for its suitability for use as a bearing material. A good adaptation to the shaft material and a good embedding capability for wear particles are basic requirements that a bearing material must fulfil in order to prevent severe damage to the shaft and bearing.

Knowledge of possible correlations between alloy composition and material hardness, both at the macroscopic and microscopic level, is therefore essential. Results from microhardness measurements of alloys that predominantly solidify in a single phase are shown in Figure 8, i.e., the alloy compositions are in the single-phase regions of the equilibrium phase diagram. The hardness values were measured at arbitrary positions on the samples, with approximately $0.5 \mathrm{~mm}$ distance between two indents. In the plot, the values are sorted by size (rank sort), therefore the plot does not show any correlation of the hardness with its location in the microstructure-it is a solely statistical analysis. The solid curves are calculated values based on the $\mathrm{Cu}$ microsegregation as derived from the phase-field simulation. We suggest a correlation between the hardness and the local $\mathrm{Cu}$ concentration following the relationship $\mathrm{HB}^{\mathrm{i}}=\mathrm{HB}_{0}{ }^{\mathrm{i}}+\mathrm{a}^{\mathrm{i}} \cdot[\mathrm{Cu}]^{\mathrm{i}}$, where $\mathrm{HB}_{0}{ }^{\mathrm{i}}$ is the hardness of phase $\mathrm{i}$ with zero $\mathrm{Cu}$. For the $\varepsilon$-phase $\mathrm{CuZn}_{4}$, the dependence from the $\mathrm{Cu}$ concentration is attributed to the difference from the reference concentration $[\mathrm{Cu}]_{0}{ }^{\varepsilon}$, thus the hardness model reads: $\mathrm{HB}^{\varepsilon}=\mathrm{HB}_{0}{ }^{\varepsilon}+\mathrm{a}^{\varepsilon} \cdot\left([\mathrm{Cu}]^{\varepsilon}-[\mathrm{Cu}]_{0}^{\varepsilon}\right)$. The experimental data for $\mathrm{ZnAl1Cu18}$ show data points with low hardness values. These points can be attributed to indents, which are in microstructure regions that show residual amounts of the $\eta$ phase.

Experimentally, it would be a large effort to measure the local $\mathrm{Cu}$ concentration, whereas it is a direct result from the simulation. The variation in the computed hardness values, again sorted from minimum to maximum, reflects the distribution of local $\mathrm{Cu}$ concentrations in the simulation domain. The good match of the model data with the experimental distribution is evidence that the hardness in all three phases, $\eta, \beta$ and $\varepsilon$, depends on the (local) Cu concentration. For $\eta$ in ZnAl1Cu0.7 and $\beta$ in

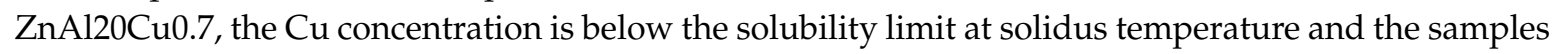
were measured in the as-cast state, i.e., without any subsequent heat treatment. Therefore, it is likely that, at least partially, the impact of $\mathrm{Cu}$ on hardness is caused by solid solution strengthening, as has already been reported by Savaskan et al. [5,11,23].

From the diagram and the modeling, one can infer that $\eta$ is the phase with the lowest hardness, and $\varepsilon$ is the one with clearly the highest hardness. One should keep in mind that $\beta$ decomposes into $\eta$ and $\alpha^{\prime}$ via a eutectoid reaction, thus the hardness values for $\beta$ should be considered rather as an effective value for a composite structure and not as a value for a single phase.

In the following, we will discuss the measured macroscopic Brinell hardness from the as-cast samples and show that the data follow a simple mixture rule. The macroscopic hardness was determined by Brinell hardness measurement HBW10-2.5/62.5/15. The measured hardness for alloys with different aluminum contents and thus different $\beta$-phase contents is shown in Figure 9. As was to be expected from the results of the microhardness measurements, an increase in the $\beta$-phase content leads to an increase in the macroscopic hardness. Extrapolating the hardness to a complete $\beta$-phase sample yields $117 \mathrm{HB}$. The values from the microhardness measurements are systematically below the values from a macroscopic indent. We attribute this to a different deformation behavior on the different scales.

The hardness increases monotonously with the $\beta$-phase fraction. Except from the alloy with $2 \%$ $\mathrm{Al}$, the hardness follows a linear relationship: $\mathrm{HB}=\mathrm{f}_{\eta} \cdot \mathrm{HB}^{\eta}+\mathrm{f}_{\beta} \cdot \mathrm{HB}^{\beta}$, where $\mathrm{f}_{\mathrm{i}}$ is the phase fractions 
and $\mathrm{HB}^{\mathrm{i}}$ is the hardness of the individual phases, in this case with $0.7 \mathrm{wt} . \% \mathrm{Cu}$. The calculated curve in Figure 9 is based on $\mathrm{HB}^{\eta}=72.5$ and $\mathrm{HB}^{\beta}=117.5$.

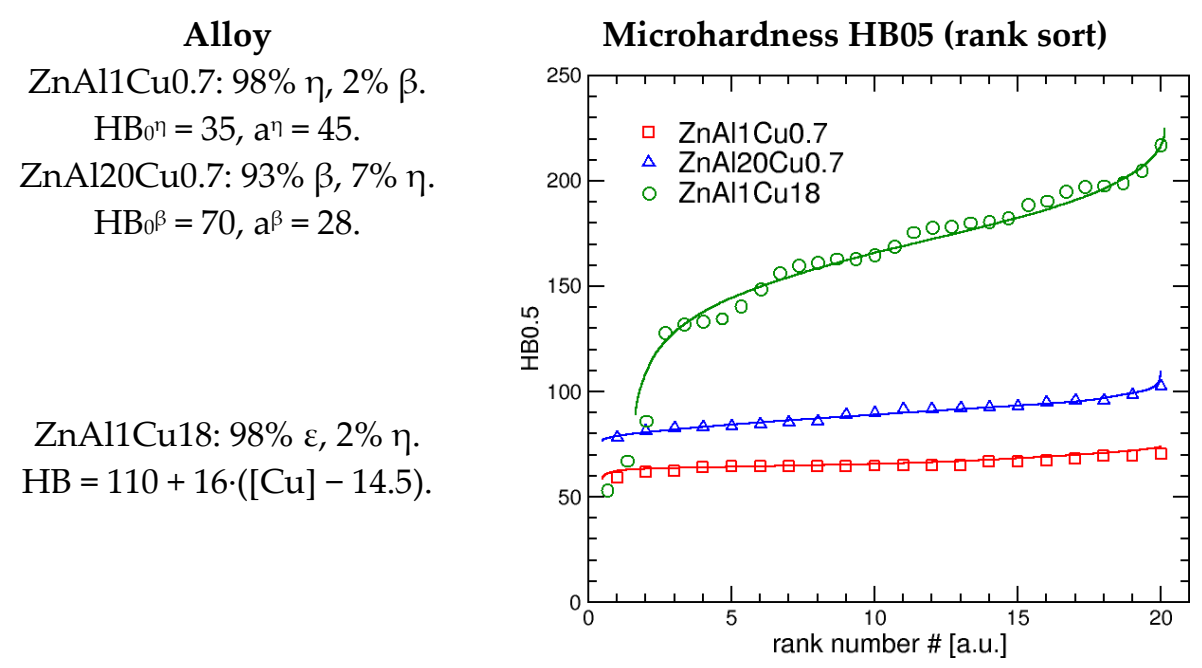

Figure 8. Measured and simulated microhardness for as-cast samples. In the left column, the phase fractions after solidification as derived from the simulations and the parameters for the hardness model are shown.

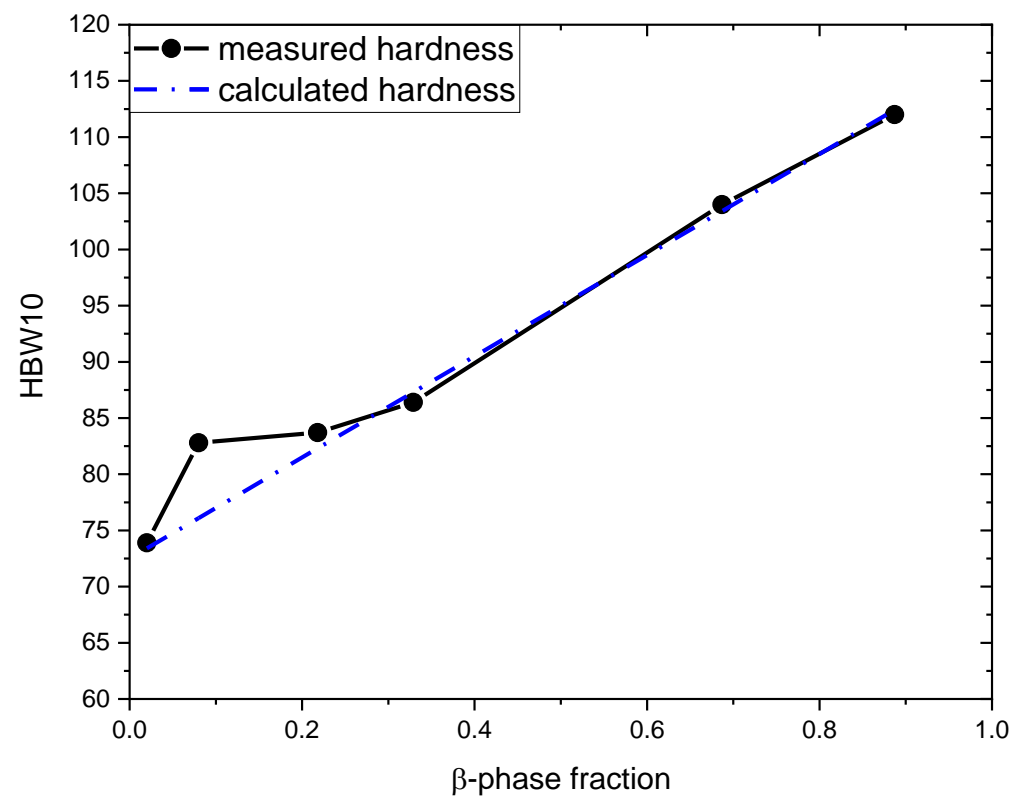

Figure 9. Macroscopic hardness of $\mathrm{ZnAl}_{x} \mathrm{Cu} 0.7$ alloys for different $\beta$-phase fractions, i.e., different Al compositions.

The dependency of macroscopic hardness on copper content shows a nonlinear behavior, as can be seen for the macroscopic hardness of $\mathrm{ZnAl} 5.5 \mathrm{CuX}$ shown in Figure 10. In the range below $1.5 \mathrm{wt}$ \% copper, barely any formation of the $\varepsilon$ phase takes place, but the hardness increases from 72 to $98 \mathrm{HB}$. Again, this increase can be attributed to solid solution hardening. For $\mathrm{Cu}$ concentrations below $1.5 \mathrm{wt} \%$, the phase fractions of $\beta$ and $\eta$ only weakly change for different $\mathrm{Cu}$ concentrations and we can describe the hardness by the relation $\mathrm{HB}=\left(\mathrm{f}_{\eta} \cdot \mathrm{HB}^{\eta}+\mathrm{f}_{\beta} \cdot \mathrm{HB}^{\beta}\right)+\mathrm{a} \cdot[\mathrm{Cu}]$, where $\mathrm{a}=21.4 / \mathrm{wt}$. $\%$. The hardness of a Cu-free ZnAl5.5 alloy with 33\% $\beta$ and $67 \% \eta$ would be less than $70 \mathrm{HB}$.

For $\mathrm{Cu}$ concentrations above $1.5 \mathrm{wt} . \%$, the $\varepsilon$ phase becomes stable and its amount then increases linearly with the $\mathrm{Cu}$ concentration. The formation of $\varepsilon$ gives an upper limit for $\mathrm{Cu}$ in solid solution and 
therefore for the hardness of the $\beta / \eta$ microstructure. The microhardness measurements for ZnAl1Cu18 prove that the $\varepsilon$ phase is considerably harder than $\beta$ and $\eta$ with a noticeable effect on the macroscopic hardness. An even small increase in $\mathrm{Cu}$ from 1.4 to $3 \mathrm{wt} \%$ increases the phase fraction of $\varepsilon$ from 0 to $13 \%$ with a corresponding hardness increase from 98 to 110 . Again, it can be described by a linear relationship of the form $\mathrm{HB}=\left(\mathrm{f}_{\eta} \cdot \mathrm{HB}^{\eta}+\mathrm{f}_{\beta} \cdot \mathrm{HB}^{\beta}\right)_{\max }+\mathrm{a} \cdot[\mathrm{Cu}-1.4]$, where $\mathrm{a}=6.25 /$ wt. $\%$ and the constant offset $(\square)_{\max }=102.5$.

Higher phase fractions of the $\varepsilon$ phase are not desirable in plain bearing applications due to the brittle and abrasive effect.

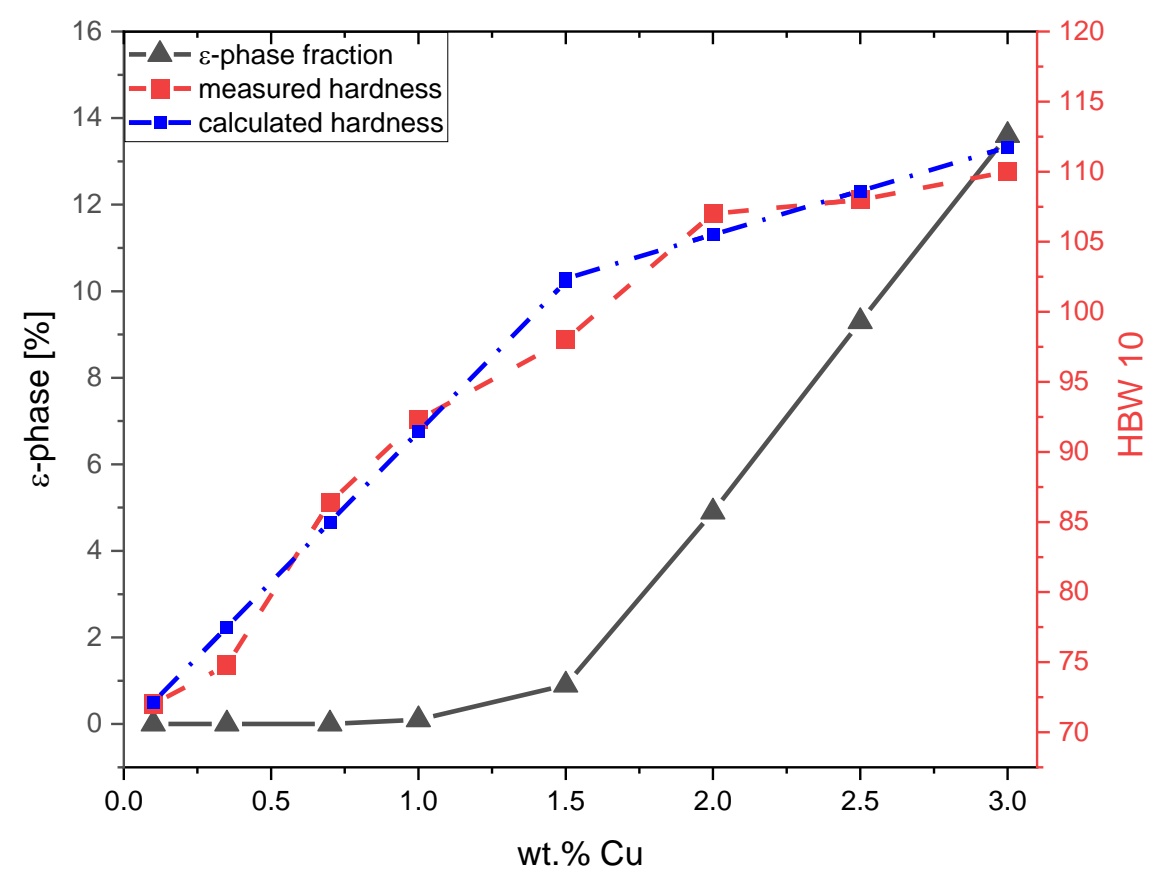

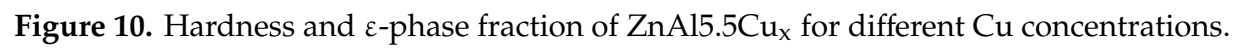

\section{Summary}

As shown in the results, spatially resolved phase-field simulations could provide good correlations with the as-cast microstructures of a variety of $\mathrm{ZnAlCu}$ bearing alloys. The comparison between the simulation and microscopic analysis of casted alloy samples demonstrates that simulations can be used to predict the microstructure of alloys in the ternary $\mathrm{Zn}-\mathrm{Al}-\mathrm{Cu}$ system in the range of [Al] $=0-25 \mathrm{wt} . \%$ and $[\mathrm{Cu}]=0-20 \mathrm{wt} . \%$. Furthermore, the macroscopic hardness correlates with the microstructure, in particular with the phase fractions and the $\mathrm{Cu}$ concentration. Results from a simple model based on mixture rules are in good agreement with the measured values, especially for variations in aluminum content which determines the $\beta$-phase fraction. $\mathrm{Cu}$ has apparently two different effects: it strengthens the individual phases by solid solution hardening and above $1.4 \mathrm{wt} . \%$, it leads to the formation of $\varepsilon-C u 4 Z n$ which shows more than two times larger hardness values compared to $\beta$ and $\eta$.

Author Contributions: Conceptualization, casting and mechanical tests were performed by S.G.; methodology, visualization and simulation were carried out by M.A.; supervision and project administration by A.B.-P. All authors have read and agreed to the published version of the manuscript.

Funding: The presented results are derived from IGF project $20165 \mathrm{~N}$ of the "FVA Research Association of the Drive Technology" which was funded within the scope of joint collaborative program "IGF" by the Federal Ministry for Economic Affairs and Energy, following a decision of the German Bundestag.

Conflicts of Interest: The authors declare no conflict of interest. 


\section{References}

1. Czichos, H.; Habig, K. Tribologie Handbuch.Tribometrie, Tribomaterialien, Tribotechnik; Springer Fachmedien: Wießbaden, Germany, 2015.

2. Savaskan, T.; Murphy, S. Sliding wear of cast zinc-based alloy bearings under static and dynamic loading conditions. Wear 2002, 252, 693-703. [CrossRef]

3. Li, H.; Liu, Y. Effect of zirconium on the microstructure and mechanical properties of $\mathrm{Zn}-4 \% \mathrm{Al}$ hypoeutectic alloy. J. Alloy. Compd. 2014, 592, 127-134. [CrossRef]

4. Zhang, L.; Chen, M. Structure and properties of an as-cast zinc-based alloy with high strength and wear resistance. J. Mater. Sci. Lett. 1998, 17, 1903-1905. [CrossRef]

5. Savaskan, T.; Hekimoglu, A. Microstructure and mechanical properties of Zn-15Al-based ternary and quaternary alloys. Mater. Sci. Eng. A 2014, 603, 52-57. [CrossRef]

6. Choudhury, P.; Das, S. Effect of Ni on the wear behavior of a zinc-aluminum alloy. J. Mater. Sci. 2002, 37, 2103-2107. [CrossRef]

7. Dorantes-Rosales, H.; Victor, M. Microstructure characterization of phase transformations in a Zn-22 wt $\% \mathrm{Al}-2$ wt\%Cu alloy by XRD, SEM, TEM and FIM. J. Alloy. Compd. 2000, 313, 154-160. [CrossRef]

8. Mojaver, R.; Shahverdi, H. Relationship between cooling rate, microstructure features and wear behavior in end-chill cast Zn-27\%Al alloys containing more than 2\% Cu. Wear 2011, 271, 2899-2908. [CrossRef]

9. Jareno, E.; Castro, M. The effects of $\mathrm{Cu}$ and cooling rate on the fraction and distribution of epsilon phase in Zn-4Al-(3-5.6)Cu alloys. J. Alloy. Compd. 2010, 490, 524-530. [CrossRef]

10. Savaskan, T.; Pürcek, G. Effect of copper content on the mechanical and tribological properties of ZnAl27-based alloys. Tribol. Lett. 2003, 15, 257-263. [CrossRef]

11. Liang, S.; Schmid-Fetzer, R. Thermodynamic assessment of the Al-Cu-Zn system, part III: Al-Cu-Zn ternary system. CALPHAD 2016, 52, 21-37. [CrossRef]

12. Zhu, Y. Phase transformations of eutectoid Zn-Al alloys. J. Mater. Sci. 2001, 36, 3973-3980. [CrossRef]

13. Zhu, Y.; Lee, W. Tensile deformation-induced phase transformation in cast Zn-Al-based alloy (ZnAl7Cu3). Mater. Res. Bull. 2003, 38, 1851-1858. [CrossRef]

14. Krupinski, M.B.K. Influence of cooling rate on crystallisation kinetics on microstructure of cast zinc alloys. J. Therm. Anal. Calorim. 2014, 118, 1361-1367. [CrossRef]

15. Petzow, G. Metallographisches Ätzen 5. Auflage; Borntraeger Verlag: Berlin, Germany, 1976.

16. ACCESS. Available online: www.micress.de (accessed on 29 May 2020).

17. Böttger, B.; Eiken, J. Phase-field simulation of microstructure formation in technical castings—A self-consistent homoenthalpic approach to the micro-macro problem. J. Comput. Phys. 2009, 228, 6784-6795. [CrossRef]

18. Böttger, B.; Apel, M.; Budnitzki, J.; Eiken, G.; Laschet, G.; Zhou, G. Calphad Coupled Phase-field Model with Mechano-Chemical Contributions and its Application to Rafting of $\gamma^{\prime}$ in CMSX-4. Comput. Mater. Sci. 2020, 184, 109909. [CrossRef]

19. Böttger, B.; Eiken, J. Phase field simulation of equiaxed solidification in technical alloys. Acta Mater. 2006, 54, 2697-2704. [CrossRef]

20. Böttger, B.; Eiken, J.; Apel, M. Multi-Ternary Extrapolation Scheme for Efficient Coupling of Thermodynamic Data to a Multi-Phase-Field Model. Comput. Mater. Sci. 2015, 108, 283-292. [CrossRef]

21. Carré, A.; Böttger, B.; Apel, M. Implementation of an antitrapping current for a multicomponent multiphase-field ansatz. J. Cryst. Growth 2013, 380, 5-13. [CrossRef]

22. Eiken, J. Numerical solution of the phase-field equation with minimized discretization error. In Numerical Solution of the Phase-Field Equation with Minimized Discretization Error; IOP Publishing Ltd.: Bristol, UK, 2012.

23. Savaskan, T.; Hekimoglu, A. Relationships between mechanical and tribological properties of $\mathrm{Zn}-15 \mathrm{Al}$ alloys. Int. J. Mater. Res. 2016, 107, 646-652. [CrossRef]

Publisher's Note: MDPI stays neutral with regard to jurisdictional claims in published maps and institutional affiliations.

(C) 2020 by the authors. Licensee MDPI, Basel, Switzerland. This article is an open access article distributed under the terms and conditions of the Creative Commons Attribution (CC BY) license (http://creativecommons.org/licenses/by/4.0/). 